\title{
Dietary Habits and Caries Experience Among 9-year-old School Children
}

\author{
Mina Biria ${ }^{1}$, Maryam Amini' ${ }^{2}$, Minoo Babaei ${ }^{3}$, Arezoo Ebn Ahmady ${ }^{4}$, Harry A. \\ Lando $^{5}$ and Gholamreza Eslami Amirabadi ${ }^{6}$ \\ ${ }^{1,3}$ Department of Pedodontics, Dental School, Shahid Beheshti University of Medical Sciences, \\ Daneshjou BLVD, Velenjak, Tehran, Iran \\ ${ }^{2}$ Biostatistics Department, Nutrition Institute, Shahid Beheshti University of Medical Sciences, \\ Shahrak Qods, Tehran, Iran \\ ${ }^{4}$ Department of Community Oral Health, Dental School, Shahid Beheshti University of Medical \\ Sciences, Daneshjou BLVD, Tehran, Iran
}

${ }^{5}$ Division of Epidemiology and Community Health, School of Public Health, University of Minnesota, Minneapolis, USA

${ }^{6}$ Department of Orthodontics, School of Dentistry, Shahed University, Italy St., Vesal Shirazi Ave., Tehran, Iran

Correspondence should be addressed to: Arezoo Ebn Ahmady; a.ebnahmady@sbmu.ac.ir

Received date: 18 May 2014; Accepted date: 16 July 2014; Published date: 13 March 2015

Academic Editor: Özlem Marti I Akgün

Copyright (C) 2015. Mina Biria, Maryam Amini, Minoo Babaei, Arezoo Ebn Ahmady, Harry A. Lando and Gholamreza Eslami Amirabadi. Distributed under Creative Commons CC-BY 4.0

\begin{abstract}
Research Motivation: Despite improvement of the trends in levels and experiences of dental caries in developed countries, it remains prevalent and is increasing in some developing countries. In this study we assessed the relationship between dietary regimens and dental caries in 9-year-old students in Tehran, Iran. Research Design/Methodology: The sample was selected by using multi-stage sampling from all the public primary schools in Tehran. 560 students were assessed using WHO questionnaires and dental examinations according to WHO criteria by indices of dmft and DMFT. The frequency of nutritional snacks consumed was determined in the following week on each individual. The acquired data were described according to abundance charts and indices of means and standard deviations. A linear regression test also was used. Main findings and implications: The mean dmft and DMFT of the students were 3.93 and 0.79 respectively. The study showed that the use of snacks such as cream-filled biscuits $(\mathrm{P}=0.030)$, plain cakes $(\mathrm{P}=0.048)$, cookies $(\mathrm{P}=0.008)$, caramel cream $(\mathrm{P}=0.009)$, milk-based ice creams $(\mathrm{P}=0.017)$, hard candies $(\mathrm{P}=0.003)$, popcorn $(\mathrm{P}=0.013)$, cheesy snacks $(\mathrm{P}=0.000)$, and bananas $(\mathrm{P}=0.002)$ significantly increased $\mathrm{dmft}$ in the study group. Furthermore, the use of snacks such as pistachios $(\mathrm{P}=0.036)$, cookies $(\mathrm{P}=0.03)$, caramel cream $(\mathrm{P}=0.048)$ and sugar-based chewing gums $(\mathrm{P}=0.008)$ showed a consequential relationship with the increase in DMFT. According to the results, the variety of the consumed snacks was high among 9-year-old students. The dietary habits including Oranges, Pies and Caramel Cream affected the incidence of the dental caries in both deciduous and permanent teeth.
\end{abstract}

Keywords: Dental caries, Diet, Children

Cite this Article as: Mina Biria, Maryam Amini, Minoo Babaei, Arezoo Ebn Ahmady, Harry A. Lando and Gholamreza Eslami Amirabadi (2015), "Dietary Habits and Caries Experience Among 9-year-old School Children ", JMED Research, Vol. 2015 (2015), Article ID 336945, DOI: 10.5171/2015.336945 


\section{Introduction}

Dental caries is an infectious disease, related to dietary regimen which is mainly dependent on the existence of bacteria inside the oral cavity; however, Mobley (2003) mentioned that its occurrence and advancement are also under the influence of other contributing factors such as saliva, absorption of fluoride, dental anatomy, dental hygiene, age, and body health among other things.

The importance of dietary regimen and its influence on dental caries is well established in numerous studies. Waldman (2000) revealed that sucrose which is abundantly present in ready-made food and sweet beverages is considered the main etiologic factor in tooth decay.

There are considerable numbers of studies that found fermentable carbohydrates to have a significant effect on the initiation and advancement of dental caries (Bibby ,1975; Finn et al., 1975; Gustaffson ,1954; Newburn ,1979; Rugg-Gunn et al., 1984; Shaw ,1983;Woodward et al.,1994). Although in a research study by Woodward et al., (1994) the relationship between the dietary regimen and dental caries has not been yet confirmed, there is a significant relationship between them in developing countries. There is limited information concerning the consumption of different foods (like sugary materials) or their consumption patterns in developing countries. Nevertheless, it is doubtless that the changes in taste, employment of the women outside the household, and exposure to advertisements in the media have increased the appetite of the public for soft drinks and sweet snacks between meals. Meanwhile, the consumption of these kinds of snacks is on the rise, especially by students which might be a contributing factor to the higher risk of dental caries. Currently, the school cafeterias of Iran offer a wide selection of these sticky and sweet snacks without any supervision, which has raised concerns about the students' dental caries.

Kashket et al., (1996) elaborated that the snacks are usually available in two major groups: low starch and high sucrose or high starch and low sucrose consumption, the snacks containing low starch lower the plaque $\mathrm{PH}$ immediately and are quickly washed up from the oral cavity, but the snacks containing high amounts of starch stay in the mouth for at least twenty minutes and leave their harmful effects. The process of disintegration of starchy material takes a long time which in turn offers more sugar to the microorganisms. Therefore, starch rich snacks cause more dental caries compared to snacks containing sucrose. Grenby (1990) and Kashket et al., (1996) mentioned that the retentive properties of the foods should also be considered, because the consumption of retentive sugary foods brings about high levels of dental caries.

Moynihan et al., (2004) revealed that the more important factor in the relationship between the dietary regimen and dental caries is the frequency of the use of sugary materials and not its quantity. According to Moynihan et al., (2004) a diet containing vegetables; fruits, which contain Vitamin C such as tangerine and oranges; and dairy products like milk and yogurt provide the body with enough calcium which could be important in prevention of dental caries.

The aim of the study was to determine the relationship between dietary habits and dental caries experience among 9-year-old students of elementary schools of districts 4, 7 \& 5 of Tehran, Iran during 2011.

\section{Subjects and Methods}

The sample of 9-year-old primary school children was selected by multi-stage sampling from the public primary schools in Tehran. There are great socioeconomic differences among households in various districts of Tehran. We tried to study sufficient samples from city center of Tehran. However, one might argue that a sample from some districts of a city is not necessarily representative of the entire city. In general this is true, but since Tehran has became a multicultural metropolitan area with a mixture of different socioeconomic groups and ethnic backgrounds, a sample of some districts in 
the city center (who has a middle socioeconomic status) could reduce these differences.

The Ministry of Education with the coordination and ethical approval of the Deputy Office for Health Affairs, Shahid Beheshti University of Medical Sciences provided a list of primary schools. From this list, 14 schools in districts 4,7 \& 8 of Tehran City, Iran were randomly selected. Thereafter, one third-year class (9- yearold) from each school was randomly selected since this age group is exactly in the middle of mixed dentition stage (between 6 to12 years old) and students were identified. We invited 670 students and parents to participate in the study. A total of 560 subjects (332 girls and 228 boys) and their mothers voluntarily participated and correctly completed the questionnaire (response rate $=83 \%$ ). The study started from April to June 2011.

The data came from a clinical examination of the children and a self-administered questionnaire for mothers. Each child was asked to take home a cover letter along with a consent letter to be completed by their parents and returned to school within 7 days. The cover letter to the parents explained the main aspects of the project and the clinical examinations to be given to the children. The clinical examination was performed for assessing students' oral health by using a disposable mirror, a sterile probe and a blue and white headlamp under natural light on a regular chair. This examination was carried out by a trained senior dental student in locations convenient for clinical examination in the schools.

To prevent inter-rater bias and avoid inconsistency between trained dentists (how well examiners agree with guidelines) all clinical examinations were delivered by a single senior dental student. The examiner went through a lengthy training process conducted by two experienced and calibrated dentists. After the training, the two trainers determined that the dental student was ready to do the clinical examinations and the first examination result of the dentist was checked and observed by the trainers. The reports of the trainers were reviewed again by the Project Coordinator, who then determined when the dentist was ready to work alone.

Efforts to attain a high degree of reliable judgment by the trainers continued in order to achieve and maintain calibration (this was accomplished through supplementary training in order to address any discrepancy encountered by the examiner during the dental examination and also to complete the standard World Health Organization form and improve the procedure).

The calibrated examiner, a senior student of dentistry, examined $10 \%$ (selected randomly) of the cases $(n=56)$ under the guidance of Principal Investigator and repeated the examination after 14 days in order to check the intra-examiner consistency (The weighted kappa coefficient was reported 0.79 ).

The contents of the questionnaire which was primarily structured were designed by the first (dentist) and second (nutritionist) authors based on similar and preliminary research in other countries (Milgrom et al., 2000), and also a research in Iran (Mossahebet al., 2011) and its psychometric properties were evaluated in terms of face and content validity through a panel discussion with seven academic staff in Iran who had experience in this subject (including two nutrition, one public health, one education, and one dental public health expert, as well as one psychiatrist and two dentists), until a convergence of opinions was reached. The reliability coefficient (Cronbach alpha) of the questionnaire was assessed through test-retest on a group of 25 mothers of school children. Respondents with three or more missing answers were excluded.

The questionnaire included questions divided into two sections: first, students' and parents' demographic characteristics including parents' age, parents' education, the frequency of tooth brushing; second, dietary intake based upon a dietary checklist in a diary in which the subjects recorded everything eaten or drunk during 
seven consecutive days. In this section, different groups of foods such as sugary materials (with focus on Iranian sugary snacking), vegetables, fruits, juices, milk, biscuits, different kinds of sandwiches, different kinds of bread, beverages, ice cream, and chewing gum were mentioned among other things.. Before distribution of the self-administered questionnaire among the study group, it was piloted in 25, 9year- old school students.

After the dental examination, the valid and reliable questionnaire was distributed among the children. Mothers were thoroughly instructed on how to complete the questionnaire. After the week of food recording, the questionnaires were gathered and analyzed. The values of DMFT and $\mathrm{dmft}$ for each individual child were recorded and for each of those indexes the mean and standard deviation of the constituent parts $(\mathrm{dt}, \mathrm{mt}, \mathrm{ft}, \mathrm{DT}, \mathrm{MT}, \mathrm{FT})$ were calculated and recorded as well.

Analyses were conducted using SPSS 17.00 statistical software (SPSS Inc., Chicago, IL,
USA). The acquired data were described according to abundance charts and indices of means and standard deviations. A linear regression test was incorporated using the backward method to determine the consumption's effects of different snacks during a week's time on the indexes of $\mathrm{dmft}$ and DMFT.

\section{Results}

In this study, 9-year-old elementary school students, mainly girls (332 girls, 59.3\%) and fewer boys (228 boys, 40.7\%) were assessed.

The results of the dental examination of the cases showed that $74(13.2 \%)$ of the students in their deciduous teeth and 364 students $(65.0 \%)$ in their permanent teeth did not have any dental caries, teeth removal or restorations. dmft of the study group was estimated 3.93(95\%CI 3.71, 4.15) and their DMFT 0.79 (95\% CI 0.69, 0.90) (Table 1).

Table 1: Indexes of central dispersion of $\mathrm{dmft}$ and DMFT variables, including their individual fractions in 9-year-old students of primary schools of districts 4, 7 \& 5 of Tehran, Iran during 2010-2011

\begin{tabular}{|l|c|c|c|c|}
\hline Variable & Mean & Minimum & Maximum & S.D. \\
\hline D & 2.52 & 0 & 10 & 2.25 \\
\hline M & 0.33 & 0 & 6 & 0.80 \\
\hline F & 1.08 & 0 & 8 & 1.69 \\
\hline dmft & 3.93 & 0 & 11 & 2.63 \\
\hline D & 0.52 & 0 & 5 & 1.04 \\
\hline M & 0.01 & 0 & 2 & 0.10 \\
\hline F & 0.28 & 0 & 5 & 0.84 \\
\hline DMFT & 0.79 & 0 & 6 & 1.28 \\
\hline
\end{tabular}

The results of the regression test using the backward method indicated that the values of dmft and DMFT were significantly higher among boys compared to the girls $(\mathrm{p}<$ 0.0001 in deciduous teeth and $\mathrm{p}<0.003$ in permanent teeth).

The cariogenicity of different foods was calculated according to the following formulas: 
$\mathrm{dmft}=\mathrm{X} \times \beta \times 5.954 \quad \mathrm{DMFT}=\mathrm{X} \times \beta \times 1.468$

In this formula $\beta$ stands for standardized coefficient and $X$ is the frequency of use of the food in question. For instance Caramel Cream has caused the decay of 0.13 of a primary tooth in a week's time, every time it was consumed, which is a significant relationship.

The study showed that the consumption of snacks including green vegetables, greengages (a kind of spring sour plum that is a favorite among Iranian children), fries, soft sweets, oranges, and fried vegetables significantly decreased $\mathrm{dmft}$, while the use of other snacks such as cream-filled biscuits, plain cakes, cookies, caramel cream, milk-based ice creams, hard candies, popcorn, cheesy snacks and bananas considerably increased $\mathrm{dmft}$ in the study group (Table 2).

Table 2: Results of the regression test in evaluation of the influences of different snacks on the value of dmft in 9-year-old students of districts 4, 7 \& 8 of Tehran, Iran, during 2010-2011

\begin{tabular}{|c|c|c|c|c|c|}
\hline & & $\begin{array}{c}\text { Unstandardized } \\
\text { coefficients } \\
\end{array}$ & $\begin{array}{c}\text { Standardized } \\
\text { Coefficients } \\
\end{array}$ & $\mathbf{t}$ & $\begin{array}{c}P \\
\text { value } \\
\end{array}$ \\
\hline & $\mathrm{B}$ & Standard Error & $\beta$ & & \\
\hline $\begin{array}{l}\text { Constant } \\
\text { Number }\end{array}$ & 5.95 & 0.48 & & 12.43 & $\begin{array}{c}0.000 \\
1\end{array}$ \\
\hline Green Vegetables & -0.12 & 0.06 & -0.09 & -1.97 & 0.049 \\
\hline Greengages & -0.47 & 0.16 & -0.13 & -2.95 & 0.003 \\
\hline Fries & -0.15 & 0.07 & -0.10 & -2.11 & 0.035 \\
\hline Soft Sweets & -0.22 & 0.10 & -0.11 & -2.23 & 0.026 \\
\hline Oranges & -0.25 & 0.08 & -0.14 & -3.13 & 0.002 \\
\hline Fried Vegetables & -0.40 & 0.20 & -0.08 & -2.03 & 0.043 \\
\hline $\begin{array}{l}\text { Cream-filled } \\
\text { Biscuits }\end{array}$ & 0.15 & 0.08 & 0.09 & 2.01 & 0.045 \\
\hline Plain Cakes & 0.15 & 0.05 & 0.12 & 2.72 & 0.007 \\
\hline Cookies & 0.19 & 0.09 & 0.09 & 2.00 & 0.047 \\
\hline Caramel Cream & 0.30 & 0.12 & 0.14 & 2.63 & 0.009 \\
\hline $\begin{array}{l}\text { Milk-based Ice } \\
\text { Creams }\end{array}$ & 0.12 & 0.05 & 0.10 & 2.40 & 0.017 \\
\hline Hard Candy & 0.33 & 0.11 & 0.13 & 2.98 & 0.003 \\
\hline Popcorn & 0.21 & 0.08 & 0.11 & 2.48 & 0.013 \\
\hline Cheesy snacks & 0.31 & 0.08 & 0.18 & 3.71 & $\begin{array}{c}0.000 \\
1\end{array}$ \\
\hline Bananas & 0.38 & 0.12 & 0.13 & 3.07 & 0.002 \\
\hline
\end{tabular}


Furthermore, eating snacks such as oranges, hamburgers, peanuts, plain milk, carrots and diet beverages significantly reduced DMFT. Meanwhile, the use of snacks such as pistachios, cookies, caramel cream and sugar-based chewing gums showed a consequential relationship with the increase in DMFT (Table 3).

Table 3: Results of the regression test in evaluation of the influences of different snacks on the value of DMFT in 9-year-old students of districts 4, 7 \& 8 of Tehran during 2010-2011

\begin{tabular}{|c|c|c|c|c|c|}
\hline & & $\begin{array}{c}\text { Unstandardized } \\
\text { coefficients }\end{array}$ & $\begin{array}{c}\text { Standardized } \\
\text { coefficients }\end{array}$ & $\mathbf{T}$ & P Value \\
\hline & B & Standard Error & $\beta$ & & \\
\hline $\begin{array}{l}\text { Constant } \\
\text { Number }\end{array}$ & 1.47 & 0.238 & & 6.16 & 0.0001 \\
\hline Oranges & -0.12 & 0.04 & -0.14 & -3.10 & 0.002 \\
\hline Hamburgers & -0.13 & 0.06 & -0.09 & -2.11 & 0.036 \\
\hline Peanuts & -0.08 & 0.04 & -0.11 & -2.24 & 0.025 \\
\hline Plain Milk & -0.04 & 0.02 & -0.08 & -1.99 & 0.048 \\
\hline Carrots & -0.17 & 0.06 & -0.13 & -3.07 & 0.002 \\
\hline Diet Sodas & -0.14 & 0.07 & -0.08 & -1.97 & 0.049 \\
\hline Pistachios & 0.06 & 0.03 & 0.10 & 2.10 & 0.036 \\
\hline Cookies & 0.10 & 0.05 & 0.10 & 2.17 & 0.03 \\
\hline $\begin{array}{l}\text { Caramel } \\
\text { Cream }\end{array}$ & 0.10 & 0.05 & 0.10 & 1.98 & 0.048 \\
\hline $\begin{array}{l}\text { Sugared } \\
\text { Chewing Gum }\end{array}$ & 0.08 & 0.03 & 0.12 & 2.64 & 0.008 \\
\hline
\end{tabular}

\section{Discussion}

Considering the effects of the consumption of snacks on dental health and also the popularity of these snacks among school children, it is of utmost importance to examine the relationship between the dietary habits and formation of dental caries.

Snacks are usually used before noon, after noon, in the evening and at bedtime (Holt RD.1991) two of which overlap school time. This calls for health professionals and planners to come up with educational programs for children that promote a healthy and rich dietary regimen.

According to the current findings, almost all of the students consumed the aforementioned snacks between meals.
Among all the factors examined, the variables of gender and consumption of cookies as snacks were shown to increase the risk of tooth decay in both deciduous $(\mathrm{p}<0.047)$ and permanent teeth $(\mathrm{p}<0.03)$. Furthermore, the use of caramel cream increased the risk of dental caries in permanent $(\mathrm{p}<0.048)$ and deciduous teeth $(p<0.009)$, while the use of oranges as snacks $(p<0.002)$ decreased the risk of formation of dental caries in both permanent and deciduous teeth.

Grenby (1990) discussed that snacks such as biscuits and pastries contain a considerable amount of sugar. Kashket et al., (1996) and Rugg-Gann (2001) revealed that the consumption of sucrose-rich starch snacks also offers a high level of sugar to the microorganisms of dental plaque 
immediately after use and for an extended period after the consumption. Marshal et al., (2005) reported that consumption of large amounts of snacks and the high frequency of their use had led to higher risk of dental caries among American children.

Alm et al., (2008) also reported through a longitudinal study that the habit of eating snacks during early childhood is related to a high rate of dental caries at the age of 15 . In the Linea and Forme study (2008), results indicated that eating too much starch and sugary snacking led to more cases of dental caries in children which is in line with the findings of the study at hand.

The results of the current study showed that the consumption of fruits such as oranges $(p=0.002)$, greengages $(p=0.003)$ and vegetables such as carrots $(\mathrm{p}=0.002)$ and green vegetables $(\mathrm{p}=0.049)$ significantly reduced the occurrence of dental caries. Eating apples also decreased dental caries, but this did not reach statistical significance $(p=0.098)$. This could be due to the fact that when eating fruits and especially sour fruits like greengages, the discharge of saliva is multi folded which prevents the decrease in plaque $\mathrm{PH}$ level and impedes the acidic attack to the teeth enamel and it also washes the oral cavity from fruit sugars which are mainly fructose. Fresh fruits have low acidogenicity; therefore, these produce lower risk of dental caries. However, in the book by Murray (1996), he mentioned that excessive consumption of fruits such as apples and grapes increases dental decay and erosion. Also Harris and Garcia-Godoy (2004) in their study mentioned that eating bananas $(p=0.002)$ was significantly related to decay of deciduous teeth which can result from the high level of acidity of bananas.

DMFT was reduced significantly with the use of milk in this study ( $\mathrm{p}=0.048)$. Levine et al., (2001) also showed that children who use moderate amounts of milk and dairy products have fewer dental caries. Also in the study conducted by Kolker et al., (2007), drinking milk is shown to be related to low levels of $\mathrm{dmft}$ which is in line with the results of this study.

Although milk contains sugar materials that cause dental decay (lactose), it also contains minerals, casein and proteins that can prevent dental caries. While drinking, milk protein is absorbed to teeth enamel and prevents its break-down according to Murray (1996).

In this study use of milk-based ice creams significantly $(\mathrm{p}=0.017)$ increased tooth decay of deciduous teeth which can be attributed to the sucrose of the ice cream that is highly damaging to teeth and is easily transformed into acid in the mouth (Mehrdad 1992)

The use of cheese decreased dental caries, but it was not significant $(\mathrm{p}=0.97)$. Tanaka et al., (2010) also did not find a strong relationship between the use of cheese and dental caries in their study. However, in Liena and Forner's study (2008) a negative relationship between the use of cheese and dental caries was observed.

Cheese is a dairy product that highly stimulates the secretion of saliva and increases the concentration of calcium in plaque. In the book by Murray (1996), he mentioned that although the use of cheese lowers PH initially, after approximately three minutes, $\mathrm{PH}$ is increased to about 7.5, and this facilitates the process of remineralization.

In our study using sugared chewing gums showed a significant relationship with the increase in DMFT ( $p=0.008)$. The Amin and Al-Abad (2008) study on foods that cause tooth decay including hard candies, chocolates and gums obtained findings consistent with the results of this study. Nuts are usually seen as foods that prevent dental caries (Mahan et al., 2008). According to the results of this study eating peanuts significantly $(\mathrm{p}=0.025)$ reduced the rate of caries of permanent teeth. Furthermore, hazelnuts, walnuts and different kinds of seeds were observed to decrease the decaying of deciduous teeth, but not to a significant degree. 
The use of Iranian special soft candy (Gaz) in this study was significantly $(p=0.026)$ related to the decrease in the caries rate of deciduous teeth. Some kinds of this soft candy (gaz) use Stevia as the main sweetener. Stevia is extracted from the plant Stevia Rebaudiana and Stevia seed is a white and crystalized powder extracted from Stevia leaves. Stevia does not contain any calories, is 250 to 300 times sweeter than sugar and prevents dental caries (Das AK, et al., (1992). Since some Iranian factories use Stevia as the sweetener there is the possibility that the users of these kinds of soft candy show an unnatural decrease in $\mathrm{dmft}$.

Some special points might be needed to be taken into consideration when comparing the results of the research on the relationship between nutritional habits and dental caries. Most of the research in this field is carried out over a short period of time during which the dental condition of the individual is investigated through 1 day, 3 days, a week or a month which is mostly related to the dental caries that are usually the outcome of mechanisms of tooth decay in the past (Burt et al., 2001). It is apparent that the effect of the use of particular foods on dental caries is observable over time. The current nutritional regimen of the child is not necessarily related to his/her past dental caries unless his/her nutritional habits do not change at all which is practically impossible. The data collected in this kind of research is not always accurate because the data are reported through parents, nurses or the children themselves and the researcher does not have supervision over the exact manner of consumption of the reported products. Also, the participants might choose to answer the questions according to the norms of the society in which they live and not exactly accurately and honestly as possible. In addition, there were no questions about the history of use of fluoride in the form of toothpastes, mouth washes or fluoride therapy in the questionnaire which is a limitation of the current study.

In different studies, different people with different social and economic backgrounds are investigated, and it is hard to find a study that includes children from differing social and economic backgrounds. Therefore, the fact that social and economic levels are indices that strongly influence general dental health also can influence the way nutritional habits influence dental caries. In addition, the methods of assessment of dietary regimens in light of the use of different questionnaires or individual interviews influence the results (Burt et al., 2001).

Future, longitudinal studies with more controlled variables including standard instructions for basic dental hygiene, use of fluoride supplements, amount of fluoride in the drinking water and socio-economic factors are needed for more accurate results.

\section{Conclusion}

The results of this study indicated that the 9-year- old studied students used a wide variety of snacks, and their dietary habits was related to their dental caries experience. The use of caramel cream and cookies increased and eating oranges decreased the risk of formation of dental caries in both deciduous and permanent teeth

\section{References}

1. Alm, A., Fahraeus, C., Wendt, L.K., Koch, G., Andersson-Gare, B., Birkhed, D. (2008). "Body adiposity status in teenagers and snacking habits in early childhood in approximal caries at 15 years of age,"Int $J$ Paediatr Dent; 18:189-96.

2. Amin, T.T. , AL-Abad, B.M. (2008). “Oral hygiene practices, dental knowledge, Dietary habits and their relation to caries among mail primary school children in $\mathrm{A}$ Hassa, SaudiArabia," Int J Dent Hyg, 20: 361-70.

3. Bibby, B.G. (1975). "The cariogenicity of snack foods and confections," J Am Dent Assoc, 90:121-32. 
4. Burt, B.A., Pal, S. (2001). "Sugar consumption and caries risk: a systematic review," J Dent Educ, 65: 1017-23.

5. Das, A.K.,Murphy, R.A., Punwany, I.C.,Nasutin ,M.P., Kinghom, A.D., (1992) "Evaluation of cariogenic potential of the intense natural sweeteners stevioside and rebaudioside," Caries Res, 26:363-66.

6. Finn, S.B.\& Glass, R.B. (1975). "Sugar and dental decay," World Rev Nutr Diet, 22:304-26.

7. Grenby, T.H. (1990). "Snack foods and dental caries: Investigations using laboratory animals," Br Dent J, 168:353-61.

8. Gustaffson, B.E. (1954). "The Vipeholm dental caries study: the effect of different levels of carbohydrates intake on caries activity in 436 individuals observed for five years," ActaOdontScand, 11: 232-64.

9. Harris, N., Garcia-Godoy, F. (2004). Primary preventive dentistry, 6th Ed.; Chap15:433-35.

10. Holt, R.D. (1991). "Foods and drinks at four daily time intervals in a group of young children," Br Dent J, 170:137-43.

11. Kashket, S., Zhang, J. , Van Houte, J. (1996). "Accumulation of fermentable sugars and metabolic acids in food particles that become entrapped on the dentition," $J$ Dent Res, 75:1885-1891.

12. Kolker, J.L., Yuan, Y., Burt, B.A., Sandretto, A.M., Sohn, W., Lang, S.W., Ismail, A.I. (2007)“Dental caries and dietary patterns in low-income African American children" Pediatr Dent, 29:457-64.

13. Levine, R.S. (2001). "Caries experience and bedtime consumption of sugarsweetened food and drink-a survey of 600 children," Community Dent Heath, 18:22831.

14. Liena, C. , Forner, L. (2008). "Dietary habits in a child population in relation to caries experience," Caries Res, 42:387-93.
15. Mahan, L.K. , Escott-Stump, S. (2008). Krause's food \& nutrition therapy. 12th ed.; Chap25:636-51.

16. Marshall, T.A., Broffitt, B., Eichenberger-Gilmore, J., Warren, J.J., Cunningham, M.A. , Levy, S.M.(2005)."The role of meal, snack, and daily total food and beverage exposures on caries experience in young children," J of Public Health Dent., 65:166-73.

17. Mehrdad, K. (1992). Dental caries and prevention Tehran: ShahidBeheshti Medical Science university, chap 2, 29-45.

18. Milgrom, P., Riedy, C.A., Weinstein, P., Tanner, A.C.R.,,Manibusan, L. , Bruss, J.(2000). "Dental caries and its relationship to bacterial infection, hyperplasia, diet, and oral hygiene in 6- to 36-month-old children," Community Dentistry and Oral Epidemiology Journal, 28:295-306.

19. Mobley, C. (2003). "Nutrition and dental caries," Dent Clin North Am, 47: 31936.

20. Mossaheb, P., Kargarnovin, Z., Malekafzali, B., Abadi, A. , Amini, M. (2011). "The relationship between food intake and dental caries in a group of Iranian Children in 2009," Journal of research in dental sciences, 7:42-50.

21. Moynihan, P., Peterson, P.E. (2004). "Diet, nutrition and the prevention of dental diseases," Public Health Nutr, 7:20126.

22. Murray, J.J. (1996).Prevention of oral diseases, 3rd Ed, Chap2,21-29.

23. Newburn, E. (1979). "Dietary carbohydrates: their role in cariogenicity," Med Clin North Am, 63: 1069-86.

24. Rugg-Gann, A.J. (2001). "Nutrition, diet and oral health," J R CollSurgEdinb, 46:32028.

25. Rugg-Gunn, A.J., Edgar, W.M. (1984). "Sugar and dental caries: a review of the evidence," Community Dent Health, $1: 85-9$ 
26. Shaw, J.H.(1983)."The role of sugar in the a etiology of dental caries: Evidence from experimental animal research," J Dent, 11:209-13.

27. Tanaka, K., Miyake, Y., Sasaki, S. (2010)."Intake of dairy products and the prevalence of dental caries in young children," J Dent, 38;579-83.
28. Waldman, H. (2000)."More than just food: What are out youngsters eating? ," ASDC J Dent Child, 67:18-20

29. Woodward, M., Walker, A.R. (1994). "Sugar consumption and dental caries: evidence from 90 countries," $\mathrm{Br}$ Dent J, 176:297-302. 